\title{
Perforated Impact Strength of Woven Kenaf Fiber Reinforced Composites
}

\author{
A.E Ismail ${ }^{1, a^{*}}$ M.A Hassan ${ }^{1, b}$, K.A Kamaruddin \\ ${ }^{1}$ Faculty of Mechanical and Manufacturing Engineering, Universiti Tun Hussein Onn Malaysia, \\ 86400 Batu Pahat, Johor, Malaysia \\ aemran@uthm.edu.my, bhd130102@uthm.edu.my, 'ckamarula@uthm.du.my
}

Keywords: Woven Kenaf Fiber, Composite, Perforated Impact, Composite Fragmentations.

\begin{abstract}
This present work investigated the perforated impact strength of woven kenaf fiber reinforced composites subjected to different projectile velocities. Three layers of woven kenaf mats were stacked with four different fiber orientations $0,15,30$ and $45^{\circ}$. The composites are fabricated using hand-layout where the woven mats were placed into the mould with a polymeric resin. The wetted composites were compressed to squeeze out the excessive resin and to eliminate the void contents. The hardened samples were shaped into a standard geometry specified by ASTM D3763. Then, the composites were perforated impact using different speeds 1,2 and $3 \mathrm{~m} / \mathrm{s}$. According to the present results, it was found that the perforated impact strength reduced when the impact velocity was increased. However, the impact strength of $15^{0}$ oriented composite was higher when compared with other types of composites.
\end{abstract}

\section{Introduction}

Nowadays, natural fiber is significantly used to fabricate various parts for non-load bearing application in automotive industries. This is due to a growing environmental awareness across the world to use environmentally friendly and sustainable materials [1-4]. The potential use of natural fibers also due to their low density and low cost in comparison with conventional fibers.

Tremendous amount of works can be found on investigating the impact responses of synthetic fiber under perforated impact [5]. However, lack of works conducted studying the influence of natural fiber on the impact strength [6]. Several works have concluded that the natural fiber composites are paramount sensitive especially under dynamic loading [1]. Most of these findings on investigated the impact responses on the randomly oriented fiber composite. While, none investigations found studied the impact strength when the fibers are weaved into specified fiber orientations.

Therefore, the present work investigates the effect of woven kenaf fiber reinforced composites under perforated impact loading. Three layers of woven mats are stacked and reoriented before it is hardened with polymeric resin. The composites are then shaped into standard geometry and dimensions. A rigid projectile is used to impact the composites at different velocities (1, 2 and $3 \mathrm{~m} / \mathrm{s}$ ). Then, the impact performances are discussed and related with the composite conditions and the fragmentation mechanisms.

\section{Methodology}

The as-received kenaf yarn as shown in Fig. 1(a). It is then weaved into a woven mat as in Fig. 1(b) using in-house designed machine. Fig. 1(c) shows the final form of plain woven kenaf mats and finally, the three woven mats are stacked using different fiber orientations such as $\left[0^{\circ} / 0^{\circ} / 0^{\circ}\right],\left[0^{\circ} / 15^{\circ} / 0^{\circ}\right],\left[0^{\circ} / 30^{\circ} / 0^{\circ}\right]$ and $\left[0^{\circ} / 45^{\circ} / 0^{\circ}\right]$ into a rectangular steel mould as in Fig. 2(a). Polyester resin is then poured into the mould and it is compressed in order to squeeze out the excessive resin and to minimize the void contents. The hardened composite plates are shaped into a standard geometry specified by ASTM D3763. 
Shimadzu Hydroshut machine shown in Fig. 2(b) is used to perforate the composite plates where the samples are placed normal to a rigid projectile using different initial impact velocities 1,2 and $3 \mathrm{~m} / \mathrm{s}$. All results corresponding with the impact tests are recorded automatically and summarized into Table 1.

\section{Results and Discussion}

Fig. 3 shows the curves of force versus time for the composite fiber oriented at different angles and perforated impact at different speeds. It is also showed that the maximum forces for all types of composites are almost similar to each other. However, the composite stiffness increased when the projectile speed is increased. In general, the curves can be divided into three regions, elastic deformation, contact between projectile and composite surface and penetration stages. It is revealed that the composites resistance during the perforated process decreased when higher projectile speed is used.

However, the composite fibers oriented with $15^{0}$ capable to resist the projectile displacement where the contact time between two surfaces increased when compared with other composites. Fig. 3(a) shows the composite responses when impacted with a $1 \mathrm{~m} / \mathrm{s}$ rigid projectile. It is obvious that the contact time for $15^{0}$ fiber oriented composite is higher than other type of orientations. Due to the sensitivity effect of natural fiber on the dynamic loading, the contact time decreased significantly when higher projectile speed is used ( 2 and $3 \mathrm{~m} / \mathrm{s}$ ) as shown in Fig. 3(b) and 3(c).

Table 1 Average energy absorption performance of woven kenaf fiber reinforced composites.

\begin{tabular}{cccccc}
\hline Sample & $\begin{array}{c}\text { Orientation of } \\
\text { woven }\end{array}$ & $\begin{array}{c}\text { Velocity } \\
(\mathrm{m} / \mathrm{s})\end{array}$ & $\begin{array}{c}\text { Maximum } \\
\text { force }(\mathrm{kN})\end{array}$ & $\begin{array}{c}\text { Impact } \\
\text { energy }(\mathrm{J})\end{array}$ & $\begin{array}{c}\text { Absorb energy } \\
(\mathrm{J})\end{array}$ \\
\hline 1 & {$\left[0^{\circ} / 0^{\circ} / 0^{\circ}\right]$} & 1 & 1.25 & 13.87 & 12.90 \\
2 & {$\left[0^{\circ} / 15^{\circ} / 0^{\circ}\right]$} & 1 & 1.34 & 20.55 & 19.93 \\
3 & {$\left[0^{\circ} / 30^{\circ} / 0^{\circ}\right]$} & 1 & 1.28 & 19.31 & 18.23 \\
4 & {$\left[0^{\circ} / 45^{\circ} / 0^{\circ}\right]$} & 1 & 1.38 & 15.93 & 13.39 \\
\hline 5 & {$\left[0^{\circ} / 0^{\circ} / 0^{\circ}\right]$} & 2 & 1.36 & 14.99 & 08.95 \\
6 & {$\left[0^{\circ} / 15^{\circ} / 0^{\circ}\right]$} & 2 & 1.43 & 17.65 & 14.03 \\
7 & {$\left[0^{\circ} / 30^{\circ} / 0^{\circ}\right]$} & 2 & 1.37 & 17.04 & 14.95 \\
8 & {$\left[0^{\circ} / 45^{\circ} / 0^{\circ}\right]$} & 2 & 1.37 & 14.80 & 09.03 \\
\hline 9 & {$\left[0^{\circ} / 0^{\circ} / 0^{\circ}\right]$} & 3 & 1.22 & 13.78 & 10.45 \\
10 & {$\left[0^{\circ} / 15^{\circ} / 0^{\circ}\right]$} & 3 & 1.25 & 13.20 & 10.30 \\
11 & {$\left[0^{\circ} / 30^{\circ} / 0^{\circ}\right]$} & 3 & 1.20 & 14.23 & 11.06 \\
12 & {$\left[0^{\circ} / 45^{\circ} / 0^{\circ}\right]$} & 3 & 1.25 & 12.61 & 09.22 \\
\hline
\end{tabular}

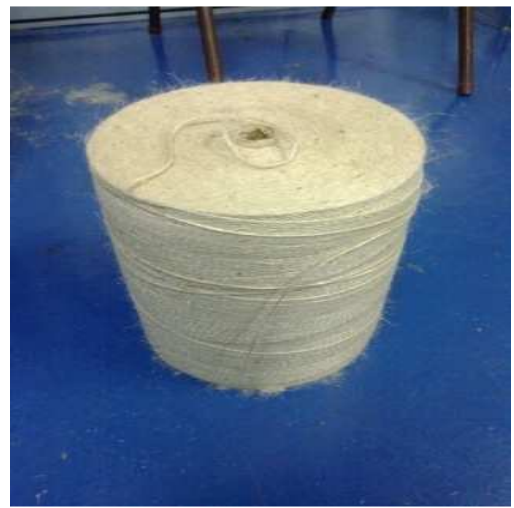

(a)

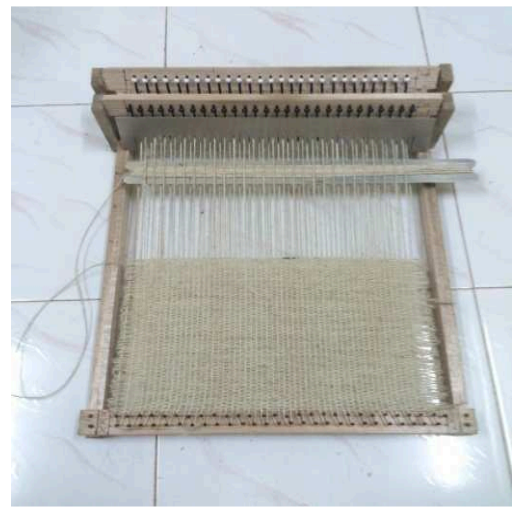

(b)

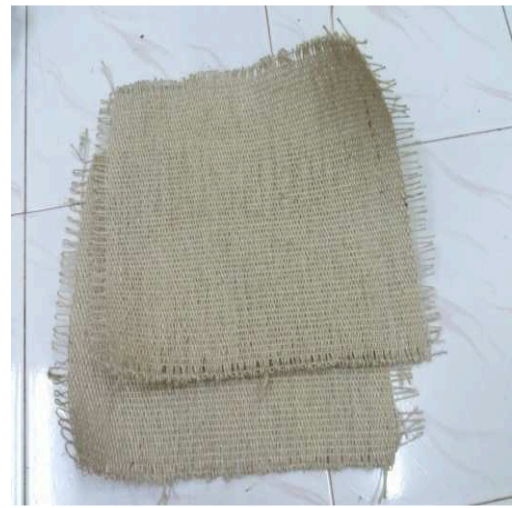

(c)

Fig. 1 (a) As-received kenaf yarn, (b) Weaving process into woven mat and (c) Final form of woven kenaf mats. 


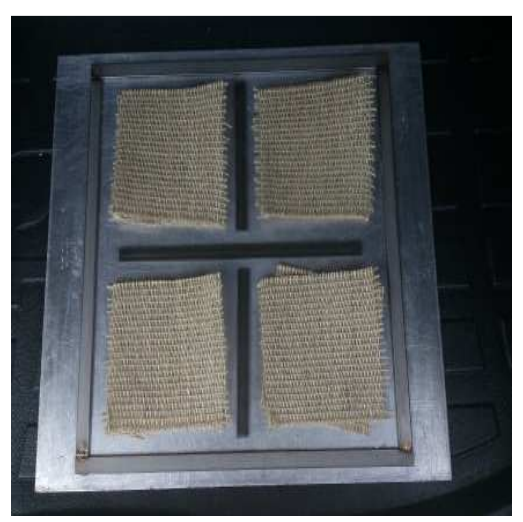

(a)

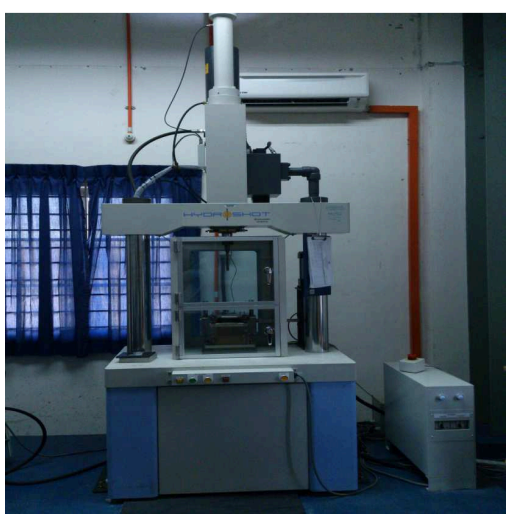

(b)

Fig. 2 (a) Kenaf mat arrangement in the mould and (b) Shimadzu Hydroshut impact machine.

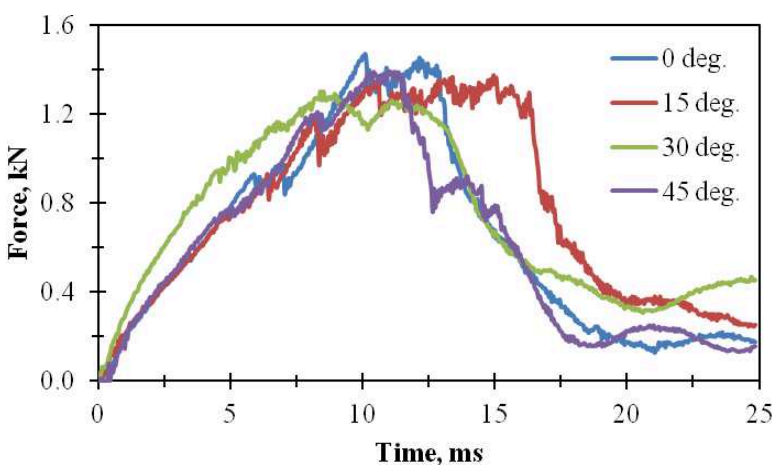

(a)

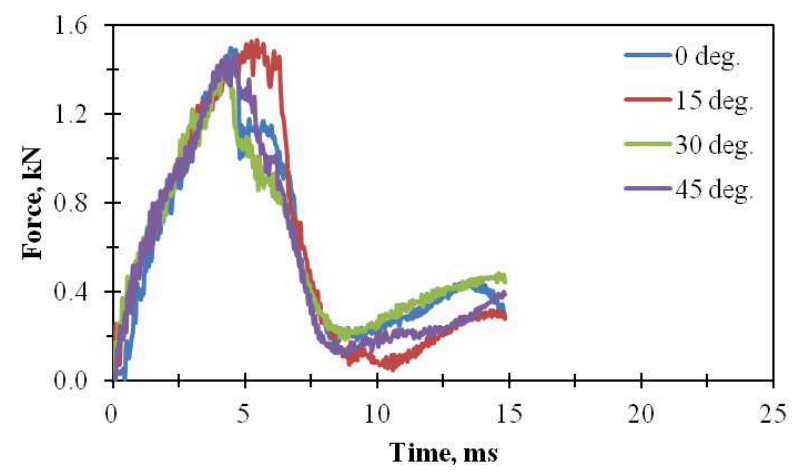

(b)

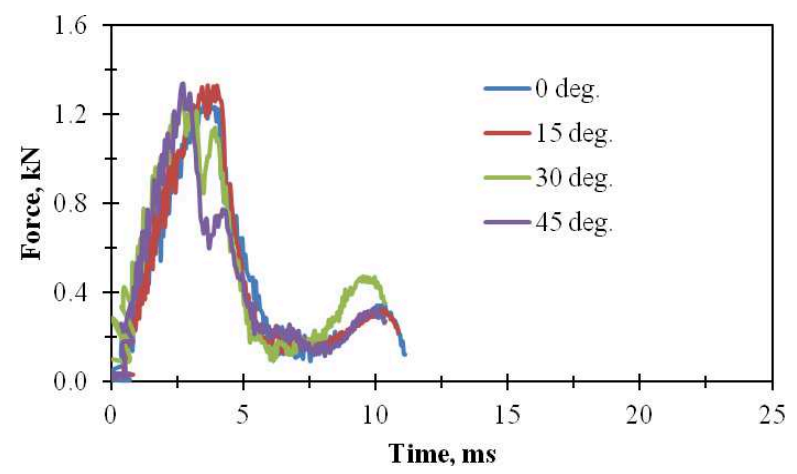

(c)

Fig. 3 Force versus time curves of perforated impact on the kenaf fiber reinforced composites subjected to different projectile speeds, (a) $1 \mathrm{~m} / \mathrm{s}$, (b) $2 \mathrm{~m} / \mathrm{s}$ and (c) $3 \mathrm{~m} / \mathrm{s}$.

Fig. 4 shows the perforated holes of the woven composites when subjected to the rigid projectiles at speed $1 \mathrm{~m} / \mathrm{s}$. It is showed that the damages around the holes are strongly depend on the fiber orientations. Composites with 0 and $15^{\circ}$ fiber orientations have an identical damage pattern where it is dispersed around the holes. However for the 15 and $45^{\circ}$ oriented fiber reinforced composites, the damaged region is concentrated around the edges of perforated holes. These damage mechanisms can be related with the energy absorption performances as listed in Table 1. It is showed that the energy absorbed by the $15^{\circ}$ fiber oriented composites are among the highest consenquently produced higher peak force. When the projectile speed is increased up to $3 \mathrm{~m} / \mathrm{s}$, all impact parameter for all types of composites have indetical results where the impact performance is not significantly affected by the fiber orientations. 


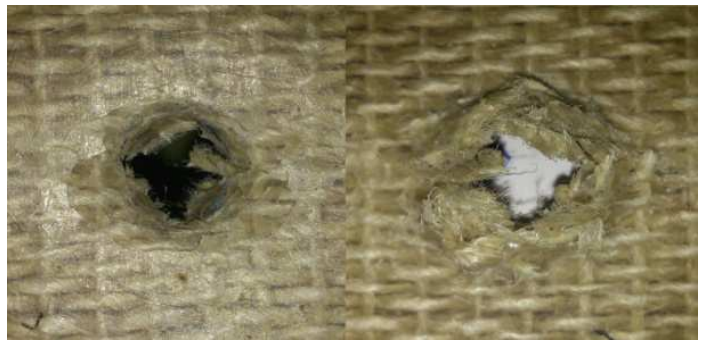

(a)

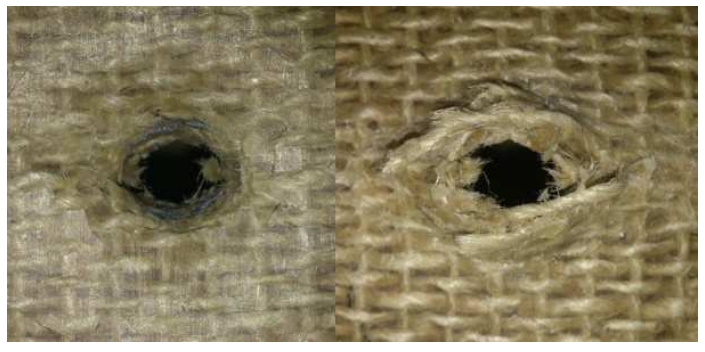

(c)

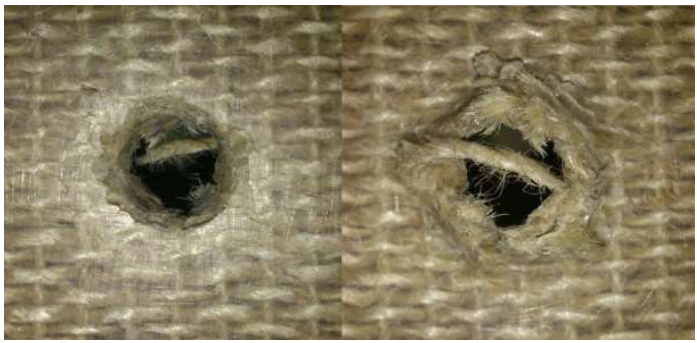

(b)

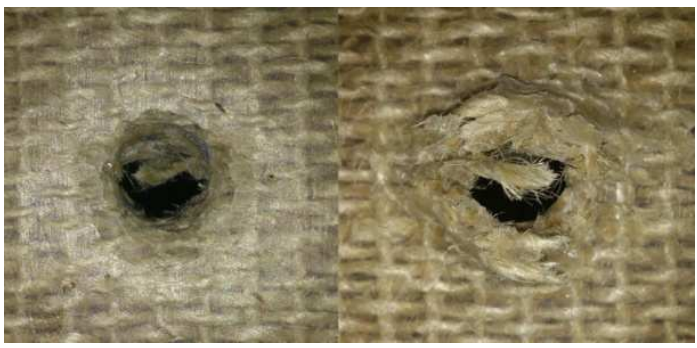

(d)

Fig. 4 Damaged zones aroud the perforated holes impacted using different speeds, (a) $0^{\circ}$, (b) $15^{\circ}$, (c) $30^{\circ}$ and (d) $45^{\circ}$ (Left: Front face and Right: Back face).

\section{Conclusion}

This paper presents the perforated impact performances on the woven kenaf fiber reinforced composites. Woven kenaf mats are orientated using different angles and impacted using different speeds of rigid projectiles. Several important conclusions can be drawn as follows:

i. Higher impact performances can be obtained if lower impact velocity is used $(1 \mathrm{~m} / \mathrm{s})$.

ii. At lower impact velocity $(1 \mathrm{~m} / \mathrm{s})$, all types of composites produced longer impact contact time compared with higher impact velocity $(>2 \mathrm{~m} / \mathrm{s})$.

iii. When impact speed is greater than $3 \mathrm{~m} / \mathrm{s}$, all impact parameters or performances have an identical results. This means that if different fiber orientations and impact speeds are used, the results are almost similar to each other.

\section{Acknowledgements}

Authors acknowledge Universiti Tun Hussein Onn Malaysia (UTHM), Office for Research, Innovation, Commercialization and Consultancy (ORICC) and Ministry of Education Malaysia for sponsoring this work through Fundamental Research Grant Scheme (FRGS) vot. 1424.

\section{References}

[1] H.N Dhakal, Z.Y Zhang, M.O.W Richardson, O.A.Z Errajhi, The low velocity impact response of non-woven hemp fibre reinforced unsaturated polyester composites, Composite Structures 81 (2007) 559-567.

[2] A.E Ismail, M.K Awang, M.H Sa'at, Tensile strength of natural fiber reinforced polyester composite, AIP Conf. Proc. 909 (2007) 174-179.

[3] A.E Ismail, M.H Zainulabidin, M.N Roslan, A.L Mohd Tobi, NHM Nor, Effect of velocity on the impact resistance of woven jute fiber reinforced composites. Applied Mechanics and Materials 465 (2014) 1277-1281. 
[4] M.N Roslan, A.E Ismail, M.Y Hashim, M.H Zainulabidin, S.N.A Khalid, Modelling analysis on mechanical damage of kenaf reinforced composite plates under oblique impact loadings, Applied Mechanics and Materials 465 (2014) 1324-1328.

[5] M.O.W Richardson, M.J Wisheart, Review of the low velocity impact properties of composites materials. J Compos: Part A 27 (1996) 1123-31.

[6] Omar Faruk, Andrzej K. Bledzki, Hans-Peter Fink, Mohini Sain, Biocomposites reinforced with natural fibers: 2000-2010, Progress in Polymer Science 37 (2012) 1552- 1596. 